\title{
FLORA DE GRÃO-MOGOL, MINAS GERAIS: UMBELLIFERAE (APIACEAE) ${ }^{1}$
}

\section{IZABEL PIMENTA CORRÊA \& JOSÉ RUBENS PIRANI}

\author{
Departamento de Botânica, Instituto de Biociências, Universidade de São Paulo, \\ Rua do Matão, Trav. 14, 321, Cidade Universitária, 05508-900 - São Paulo, SP, Brasil.
}

CORRÊA, I.P. \& PIRANI, J.R. 1999. Flora da Serra do Cipó, Minas Gerais: Umbelliferae (Apiaceae). Bol. Bot. Univ. São Paulo 18: 61-68.

CORRÊA, I.P. \& PIRANI, J.R. 2005. Apiaceae. In M.G.L. Wanderley, G.J. Shepherd, T.S. Melhem, S.E. Martins, M. Kirizawa \& A.M. Giulietti (eds.) Flora fanerogâmica do Estado de São Paulo. RiMa/FAPESP, São Paulo, p. 11-34.

MATHIAS, M.E., CONSTANCE, L. \& ARAUJO, D. 1972. Umbelliferae. In R. Reitz (ed.) Flora ilustrada catarinense. Herbário Barbosa Rodrigues. Itajaí.

STANNARD, B.L. \& ZAPPI, D.C. 1995. Umbelliferae. In B.L. Stannard (ed.) Flora of the Pico das Almas, Chapada Diamantina, Bahia, Brazil. Royal Botanic Gardens. Kew, p. 619-621.

URBAN, I. 1879. Umbelliferae. In C.F.P. Martius \& A.W. Eichler (eds.) Flora brasiliensis. Frid. Fleischer. Leipzig, vol. 11, pars 1, p. 261-354.

WOLFF, K.F.A.H. 1910. Umbelliferae. Apioideae. In H.G.A. Engler (ed.) Das Pflanzenreich. Wilhelm Engelmann. Leipzig, 228, Heft 43, p. 75-81.

WOLFF, K.F.A.H. 1913. Umbelliferae-Saniculoideae. In H.G.A. Engler (ed.) Das Pflanzenreich. Wilhelm Engelmann. Leipzig, IV-228, Heft 61, p. 1-305.

1. Flores em capítulos densifloros; plantas aculeadas ou inermes, folhas paláceas (não peltadas),

oblongas

2. Flores alvas; folhas fortemente aculeadas na margem, exceto na bainha alargada Eryngium

2 '. Flores azuis ou roxas; folhas com margem esparsamente aculeada ou apenas ciliado-aculeada, a bainha estreitada E. regnelli

E. sanguisorba

$1 '$. Flores em umbelas; plantas inermes, folhas peltadas, não oblongas.

3. Ervas prostradas ou decumbentes; fruto comprimido lateralmente com comissuras e carpóforo ausentes; dentes do cálice rudimentares

3'. Ervas eretas; fruto subcilíndrico com comissuras extensas e 2 mericarpos evidentes; dentes do cálice conspícuos Klotzschia brasiliensis

\section{Eryngium (Tourn.) L.}

Ervas rosuladas, geralmente aculeadas e glabras, bienais ou perenes. Folhas basais dísticas ou espiraladas, caulinas alternas, simples, aculeado-serreadas, lobadas ou profundamente recortadas, paralelódromas ou com nervuras anastomosando em direção à margem, base modificada em bainha invaginante. Inflorescência em capítulo denso, globoso, hemisférico ou cilíndrico, envolto na base por invólucro de brácteas rígidas, disposto em eixo terminal cimoso geralmente dicasial, fistuloso ou maciço, alongado, ereto ou às vezes decumbente e proliferante por enraizamento, pouco a muito ramoso, dotado de brácteas folhosas semelhantes às folhas basais porém menores. Flores 5-meras, bissexuadas, sésseis, cada uma na axila de uma bractéola; sépalas rígidas; pétalas cartáceas, livres, ápice inflexo, lobado, bifurcado ou fimbriado; estames 5 , inseridos em disco epigínico; ovário ínfero 2-locular, lóculos uniovulados; estiletes 2. Fruto esquizocarpo, com 2 mericarpos com canais oleíferos (vitas), lateralmente cobertos por escamas, escamas dorsais presentes ou não, escamas calicóides formando uma ou duas séries; costas indistintas; estilopódio e carpóforo ausentes.

\footnotetext{
${ }^{1}$ Trabalho realizado conforme o planejamento apresentado por Pirani et al. 2003. Bol. Bot. Univ. São Paulo 21(1): 1-24.
} 


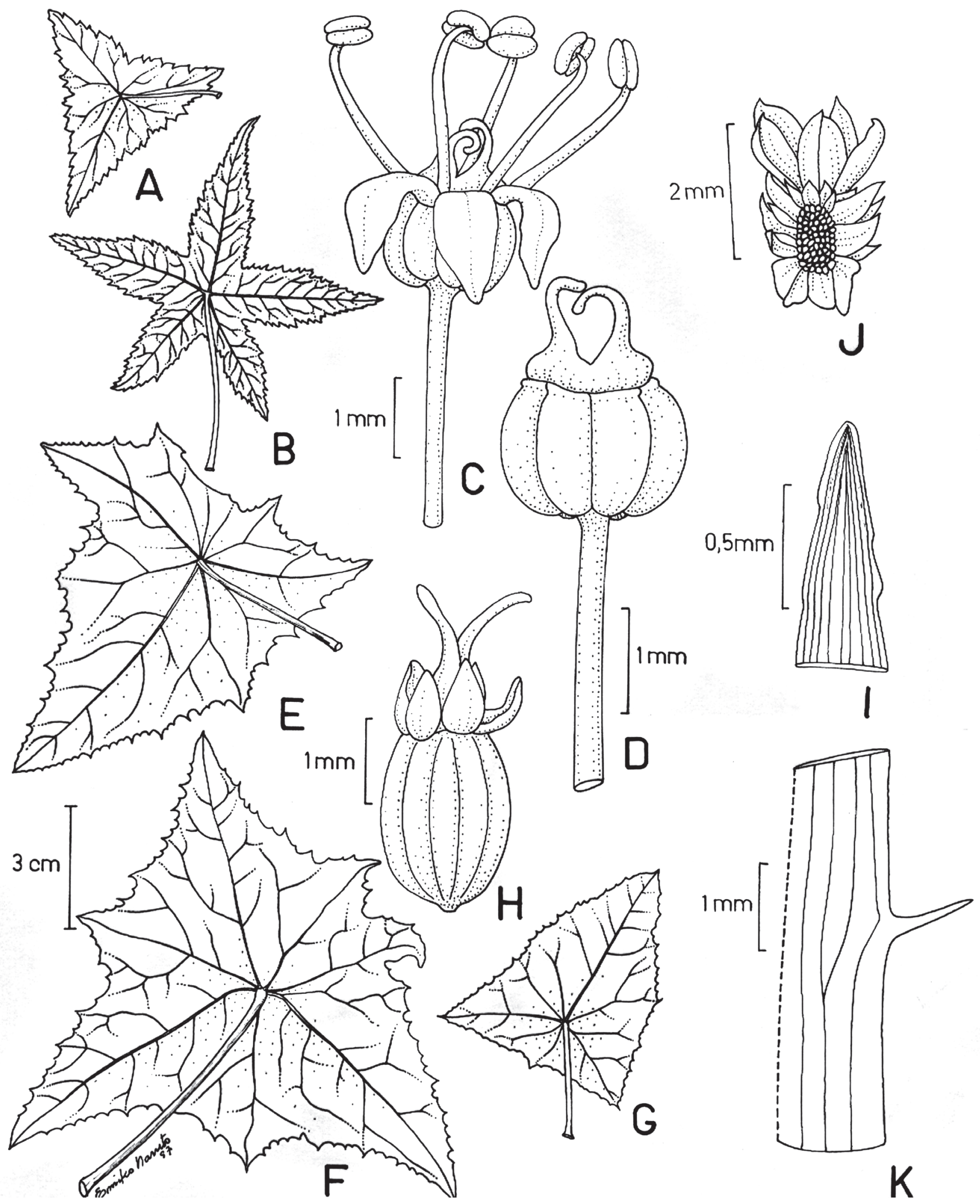

Fig. 1. UMBELLIFERAE: A-D. Hydrocotyle quinqueloba: A-B. Folhas; C. Flor; D. Fruto. E-H. Klotzschia brasiliensis: E-G. Folhas; H. Flor. I-K. Eryngium sanguisorba: I. Ápice foliar; J. Fruto imaturo; K. Detalhe da margem foliar. (A-K extraídas de Corrêa \& Pirani 1999). 
1.1. Eryngium regnelli Malme, Ark. Bot. Stockh. 3(13): 9. 1904.

Ervas eretas, até 1,5 m alt., aculeadas. Folhas basais (sub) dísticas, suberetas; lâmina 35-120 cm compr., 1-2 cm larg., lanceolada ou linear-lanceolada, alargada na base em uma bainha inteira, paralelódroma, ápice longamente atenuado, margem aculeado-ciliada (exceto na bainha inteira), os acúleos retos e solitários ou algumas vezes agrupados em 2 ou 3; folhas caulinas como as basais, mas menores, gradativamente reduzidas para o ápice. Eixo da inflorescência cilíndrico, maciço, estriado, 0,5-1,5 m compr.; capítulos densos, ovóides a subglobosos, alvo-esverdeados; brácteas involucrais 6-10, oval-lanceoladas, reflexas, ápice acuminado, margem inteira, glabras; bractéolas como as brácteas involucrais, mas menores. Flores alvas; sépalas ovais, ápice obtuso, margem inteira, escabras; pétalas oblongo-ovais, ápice 2-lobado, inflexo. Fruto ca. $2 \mathrm{~mm}$ compr., cuneado; mericarpos com escamas achatadas formando uma série calicóide e 2 alas marginais, dorsais ausentes.

\section{Pirani et al. CFCR 8971 (SPF, UC).}

Espécie distribuída do norte de Goiás e Minas Gerais até Santa Catarina. Em Grão-Mogol, foi coletada em solo arenoso de campo à beira de mata, entre gramíneas, com flores e frutos em janeiro.
1.2. Eryngium sanguisorba Cham. \& Schltdl., Linnaea 1: 239. 1826 .

Ervas eretas, até 1,5 m alt., aculeadas. Folhas basais não dísticas, suberetas; lâmina 20-60 cm compr., 0,5-2 cm larg., lanceolada ou linear-lanceolada, estreitada na base, paralelódroma, ápice agudo, margem aculeada a aculeado-ciliada; folhas caulinas como as basais, mas menores. Eixo da inflorescência cilíndrico, maciço, estriado, 0,5-1,5 m compr.; capítulos densos, ovóides, arroxeados a azulados; brácteas involucrais 8-10, lanceoladas, reflexas, ápice acuminado, margem inteira, glabras; bractéolas como as brácteas involucrais, mas menores. Flores azuis ou roxas; sépalas ovais, ápice acuminado, margem inteira a denticulada, glabras; pétalas elípticas, ápice 2-lobado. Fruto ca. $3 \mathrm{~mm}$ compr., cuneado; mericarpos com escamas laterais achatadas, dorsais vesiculosas. (Fig. 1. I-K)

Melo de Pinna et al. 52 (SPF).

Espécie da América do Sul meridional. No Brasil distribui-se nas regiões Sul e Sudeste. Em Grão-Mogol, foi coletada em campo rupestre perturbado, entre gramíneas, com flores e frutos em agosto.

\section{Hydrocotyle $\mathrm{L}$.}

Ervas perenes, glabras a pubescentes, odoríferas; caule delgado, rastejante ou subterrâneo, estolonífero; folhas alternas, simples, geralmente anguladas a lobadas; base do pecíolo não invaginante, estípulas 2, escariosas. Inflorescência em umbelas simples, às vezes prolíferas, opositifólias; invólucro presente, involucelo ausente; flores alvas, amareladas, púrpuras ou esverdeadas; cálice minúsculo ou rudimentar; fruto esquizocarpo, constituído de dois mericarpos unidos nas faces comissurais, glabro ou hirsuto, comprimido lateralmente, orbicular, reniforme ou elíptico, costas 5, carpóforo e vitas (canais oleíferos) ausentes; sementes comprimidas lateralmente, planas a convexas.

2.1. Hydrocotyle quinqueloba Ruiz \& Pavon, Fl. peruv. 3 (25): 248. 1802.

Caule rastejante a decumbente, glabro ou hirsuto; folhas peltadas, orbiculares a cruciformes ou triangulares, $5-7,5 \mathrm{~cm}$ diâm, diminutamente hirsutas a glabrescentes na face adaxial, principalmente nas nervuras, glabras a densamente hirsutas na face abaxial, lobos 3-8, uniformes ou não, agudos a acuminados, margem duplo-serreada, pecíolo $3-12 \mathrm{~cm}$ compr.; umbelas simples, 10-45 flores, brácteas involucrais escariosas, com menos de $1 \mathrm{~mm}$ compr., pedúnculo mais longo que o pecíolo, 6-20 cm compr., pedicelo 1,2-10 mm compr.; pétalas inteiras, agudas, recurvadas; fruto reniforme, 1-3 mm compr., 1-3,5 mm larg. (Fig. 1. A-D)

\section{Freire-Fierro et al. CFCR 12518 (SPF, UC).}

Espécie distribuída no Peru, Bolívia e, no Brasil, da Bahia e Goiás até o Rio Grande do Sul, freqüentemente encontrada em vegetação aberta, mas próximo da orla de matas e em clareiras, muitas vezes em locais perturbados. Em Grão-Mogol, foi coletada em terreno úmido com Sphagnum, à sombra parcial. Floresce o ano inteiro, tendo um período predominante de dezembro até março, frutificando em seguida.

\section{Klotzschia Cham.}

Ervas odoríferas, todas aparentemente acaules ou rizoma, caule aéreo cilíndrico, ereto, multiestriado, glabro; folhas alternas ou em roseta, glabras a esparsamente pilosas, peltadas, triangulares a ovais, lobadas ou não; pecíolo com invaginante, glabro; umbelas dispostas em panícula; cálice evidente, sépalas triangular-ovadas ou oval-lanceoladas; frutos subcilíndricos, 
achatados lateralmente, comissuras extensas, costas 5, obtusas, carpóforo indiviso.

\subsection{Klotzschia brasiliensis Cham., Linnaea 8: 8. 1833.}

Caule cilíndrico, ereto, glabro, multiestriado, $3,5-15 \mathrm{~cm}$ alt.; folhas alternas, às vezes agregadas quase em roseta basal, glabras, triangulares a ovais, ápice acuminado ou agudo a obtuso, margem denteada, 4,5-14 cm compr., 5-10,5 cm larg., pecíolo glabro, 2,5-18 cm compr.; umbelas 3-floras, brácteas involucrais 2, opostas, inteiras, ápice águdo; flores alvas; frutos 2-4,5 mm compr. (Fig. 1. E-H)
Cordeiro et al. CFCR 8988 (SPF); Harley et al. CFCR 6519 (SPF); Pirani et al. CFCR 11462, CFCR 12514 (SPF).

Endêmica de campos rupestres da Cadeia do Espinhaço, de Minas Gerais até a Bahia, freqüentemente em solos arenosos ou pedregosos, geralmente crescendo próximo a vertentes de água. Em Grão-Mogol, ocorre em campos rupestres, no alto da Serra, entre gramíneas em solo arenoso, entre pedregulhos, quase sempre próximo a vertentes de água. Floresce de dezembro a março, frutificando em seguida. 